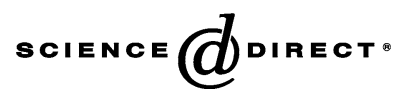

Journal of Aging Studies 19 (2005) 349-362
Journal of

AGING

STUDIES

www.elsevier.com/locate/jaging

\title{
The role of religion in mediating the transition to residential care
}

\author{
Michael J. Lowis ${ }^{\mathrm{a}, *}$, Anthony C. Edwards ${ }^{\mathrm{b}, 1}$, Chris A. Roe ${ }^{\mathrm{b}, 2}$, Albert J. Jewell ${ }^{\mathrm{a}, 3}$, \\ Michael I. Jackson ${ }^{\mathrm{a}, 4}$, W. Mannes Tidmarsh ${ }^{\mathrm{a}, 5}$ \\ ${ }^{a}$ Christian Council on Ageing, 47, Allard Close, Northampton, England, NN3 5LZ, UK \\ ${ }^{\mathrm{b}}$ University College Northampton, Park Campus, Northampton, NN2 7AL, England, UK
}

Received 4 May 2004; received in revised form 15 July 2004; accepted 20 August 2004

\begin{abstract}
Purpose: The move from independent domicile to residential care can be a traumatic experience for the elderly. This study investigated the mediatory role of the individual's religious and spiritual beliefs on coping with this transition.

Design and methods: A self-report survey design was used, and questionnaires were administered to 50 individuals who had entered residential care within the previous 12 months.

Results: The analyses showed that scores on a life satisfaction scale were significantly and positively correlated with those from a spirituality measure $(p=.033)$, from a faith in nature and humanity scale $(p=.001)$, and from an instrument to measure the use of religion as a coping measure $(p=.004)$. Contrary to the hypotheses, there were no such significant relationships with measures of either organised or non-organised religion. The relationships between variables were further explored through a path analysis.

Implications: The findings pointed to the benefits of a more personal and subjective belief system than a formal one. We concluded that it is important for all those who work with the elderly to acknowledge and
\end{abstract}

\footnotetext{
* Corresponding author. Tel.: +44 1604 785847; fax: +44 1604403578.

E-mail addresses: mike.lowis@virgin.net (M.J. Lowis), Anthony.edwards@northampton.ac.uk (A.C. Edwards), chris.roe@northampton.ac.uk (C.A. Roe), ajjewell@aol.com (A.J. Jewell), Michael.jackson@stjohnswinchester.co.uk (M.I. Jackson), anntidmarsh@home.gb.com (W.M. Tidmarsh).

${ }^{1}$ Tel.: +44 1604 892411; fax: +44 1604720636 .

2 Tel.: +44 1604 892623; fax: +44 1604720636 .

${ }^{3}$ Tel.: +441132789438 .

${ }^{4}$ Tel.: +441962854226 .

5 Tel.: +44 185864599 .
}

0890-4065/\$ - see front matter (C) 2005 Elsevier Inc. All rights reserved.

doi:10.1016/j.jaging.2004.08.003 
recognise the role that religious and spiritual beliefs may have as a coping mechanism during stressful times.

(C) 2005 Elsevier Inc. All rights reserved.

Keywords: Elderly; Life satisfaction; Religion; Spirituality; Residential care; Coping

\section{Introduction}

This study was conceived to investigate the role of religious practices and spiritual beliefs in mediating the transition of elderly people from independent domicile to residential care. The prime reasons for moving into residential care include medical emergency, inability to manage daily activities, to be near friends, or as a response to pressure from relatives (Wilson, 2000). In the UK, only $5 \%$ of people aged 65 and over reside within institutions, but this rises to $29 \%$ by the age of 85 and over (Wanklyn, 1996).

Entry into residential care has been described as the "choice of last resort" (McAuley \& Blieszner, 1985, in Bee, 1998, p. 495), or "an evil to be avoided at all costs" (Wilson, 2000, p.145). Reasons given for this include loss of independence, reluctance to live with "uncongenial" others, and guilt feelings of relatives (Campbell, 1971, in Biggs, 1993; Nicholson \& White, 1993; Townsend, 1981, in Oldman \& Quilgars, 1999). Baldwin, Harris and Kelley (1993, in Oldman \& Quilgars, 1999), however, argued that those who criticised residential care tended to ignore older people's lives prior to their admission. Some support for Baldwin et al's view comes from the work by Brown and Lowis (2003), who surveyed elderly participants in a study designed to seek confirmation for a suggested psycho-social development stage beyond Erikson's (1988) ego integrity versus despair. Elderly participants were drawn both from care homes and those living independently, but only the independent dwellers made comments about loneliness and the burden of maintaining their own homes and security.

It is, nevertheless, understandable that any event that necessitates a major life change could be seen as stressful, perhaps the more so when those involved are elderly. A move from independent domicile to residential care is likely to be voluntary if the person has a severe illness, is bedridden, or requires frequent medication, although it may be perceived by some individuals at the time as enforced. In some cases, however, people may actually be placed in nursing homes when professional intervention establishes that he or she has become a safety liability to self or others (Schaie \& Willis, 1996).

One indication of how stressful and traumatic a move to care can be is suggested by the Social Readjustment Rating Scale (SRRS) of Holmes and Rahe (1967). These authors assigned numerical stress values to a list of 43 life events that can befall a person, with the most severe receiving 100 points. A change in living arrangements is rated 26th in severity, with 25 points, but the reason for the move drastically increases the cumulative score if it were, for example, a change in health of a family member (44 points), retirement (45 points), personal illness (53 points), marital separation (65 points), or death of spouse (100 points). Evidence has been cited indicating links between recent life changes and near-future illness, and between perceived stress and SRRS scores (Bentley, 1991; Holmes \& Holmes, 1970; Rahe \& Arthur, 1978). Holmes and Holmes (1970) found in their study with participants aged 16 to 60 that an SRRS score of about 50 or over was associated with a range of physical health problems. 
A question arises concerning whether or not the effects of such stressors are inevitable, or can be ameliorated. In an interesting example of research parallel to that of the present study, Towers (2003) investigated people who were in their $70 \mathrm{~s}$ to $90 \mathrm{~s}$. He found that spiritual beliefs and, in particular, religious association over the life span had a positive impact on older persons' transition to care. Specifically, the link with spiritual matters sustained a sense of confidence in the self, and a belief that life still mattered and had a purpose. Religious affiliations provided a sense of order to their experience, so that time in care was still a period when old connections were sustained. Religion gave elderly people in care homes a sense of homeostasis - a balance between their internal selves and their external environment.

There are a number of reports in the literature on the psychological and physical benefits of religion and spirituality, with specific regard to older people, some of which could help mediate the effects of a potential traumatic event such as change of domicile. For example, a study by Kass, Friedman, Leserman, Zuttermeister, and Benson (1991), employing their original spirituality measure, revealed positive relationships between core spiritual experiences and both life satisfaction and reduction of medical symptoms scores with participants aged 25 to 72 years. Krause (1998), in his research on coping with deteriorating neighbourhoods, found that people over the age of 65 years who were involved in the church (that is, organised religion) were less likely than were those with weak institutional ties to experience a decline in their self-rated health status. Krause argued that the feeling that one is not alone during adverse times, plus the presence of like-minded people who can provide social support, is responsible for this finding. Although not specifically concerned with religion, studies by Kahn, Hessling, and Russell (2003) with elderly people found significant relationships between perceived social support and measures of psychological well-being but, interestingly, not between the former and self-rated physical health after controlling for negative affectivity.

Koenig $(2001,2002)$ carried out several investigations on the benefits to the elderly of religion. For example, he reported that nearly $90 \%$ of medical in-patients older than 60 years had indicated that they used religion to help them cope, with half of these stating that it was the most important factor that kept them going. Among the evidence cited is the notion that religious beliefs may provide older people with a form of control over health matters that their non-religious peers do not have, and that religious activities might even be associated with longer survival of up to 7 years. Koenig stated that the reason why religious beliefs provide this "control" is that religious people pray to God, believing that He is capable of intervening - they can thus do something (italics original) to help improve their situation. For a further review of additional evidence that suggests a link between religion and aspects of health, see Levin (2001).

A shortcoming of some previously reported research is that it does not always make explicit the differences between claimed benefits for organised religion that might potentially provide social support (with the actual "religious" involvement perhaps taking a secondary role), and spirituality which might involve a belief in a higher, caring entity on whom one can call for help and guidance.

The present study aimed to address these weaknesses and to investigate separately the roles of religion and spirituality during the domicile transition process. It is therefore necessary to clarify what is meant by these terms, and to consider even if they can be distinguished. We were in broad agreement with Elkins, Hedstrom, Hughes, Leaf, and Saunders (1988), who took religion to mean participation in the particular beliefs, rituals and activities of a traditional religion. By contrast, they regarded spirituality as a way of being and experiencing that comes about through awareness of a transcendent dimension, and that is characterised by values concerning the self, others, nature and life. 
MacDonald, Le Clair, Holland, Alter, and Friedman (1995) cautioned that many measures of transpersonal constructs appeared to be confounded with religion or religiosity, at least to some extent, and it is possible that one can have spiritual faith in a higher power whilst not necessarily being aligned to any orthodox religion. In similar vein, Worthington, Kurusu, McCullough, and Sandage (1996) stated that, spirituality is not necessarily marked by any alignment with a formal creed or set of doctrines. Likewise, an individual can have a deep-rooted conviction that tenets of an established creed are true, but has never experienced any personal sense of the numinous. It would thus seem desirable for researchers in these topics to make use of instruments that at least attempt to measure religion and spirituality as discrete variables: an approach that is adopted in the present study. Koenig (2002) observed that individuals who are not specifically religious might nevertheless still have spiritual needs.

It has been suggested that there are separate dimensions within the variable of religion per se. Mindel and Vaughan (1978) drew on their previous factor analysis findings to devise questions on organisational religious activity, such as attending and participating in services and other events, and non-organisational religious activities such as listening to events on radio or television, and praying alone. Krause (1998) also compiled questions to differentiate between these two aspects. The present study will draw on both of these reports for instrument design, as the impaired mobility of some care home residents might inhibit their opportunity to participate in organisational religious activities, assuming the desire be there in the first place. A somewhat different dichotomy had earlier been suggested by Allport and Ross (1967). They referred to extrinsically motivated people who use their religion for their own ends (security, sociability, distraction), and the intrinsically motivated ones who live their religion (internalise, and follow it fully). Another form of religious orientation was suggested by Batson (see for example Batson, Schoenrade, \& Ventis, 1993) and was named quest. This is marked by treating religion as an open-ended search, rather than as a diagnostic foreclosure on presumed answers.

In the present study, our primary aim was to investigate the claimed mediatory role of elderly persons' religious and spiritual beliefs on their transition to residential care. We hypothesised that scores on a life satisfaction scale, obtained from individuals who had been resident in care homes for a maximum of 12 months, would be positively correlated with several measures of organised and non-organised religion, and spirituality. As an original contribution to the domain of knowledge on this topic, we would adopt the view that religion is not a unitary concept, and thus we would assess a range of related variables. We planned to conduct a path analysis to explore the nature of any relationships found, along with indications of mediating effects. Additionally, we would use the data to explore the relationship between religious devoutness and both mental and physical health, a link that had been suggested by previous researchers.

\section{Method}

\subsection{Participants}

Fifty individuals, comprising 36 females and 14 males, responded positively to invitations to participate in this study; and they can thus be regarded as a self-selecting sample but with an attempt to recruit all those eligible in the care homes targeted. This unequal gender split reflected the trend of increased longevity of women compared with men, and was in close agreement with the $74 \%$ female 
occupancy of residential care homes in Northamptonshire (pers. com. J. Woolham, Northamptonshire Social Services 05/07/04). The mean age was 85.24 years (range=74-94, S.D.=5.46). All were permanent residents of the care homes, which means that their main needs were catered for and they were not bed-bound, although varying degrees of nursing care may have been provided. Participants were only sought who had been resident for 12 months or less, as the study was concerned with transition rather than long-term adaptation. The mean tenure was 6.84 months (range $=.50$ to 12 , S.D. $=3.45)$.

Participants recorded their marital status as: married $=6(12 \%)$, widowed $=33(66 \%)$, single $=10$ $(20 \%)$, not stated $=1(2 \%)$. Religious affiliation was recorded as: Anglican $=15(30 \%)$, Roman Catholic $=9(18 \%)$, non-conformist $=18(36 \%)$, none $=7(14 \%)$, not stated $=1(2 \%)$. Prior to the hypothesis testing to be reported later, analyses of variances were computed to see if any of these variables could have moderated the main variable of life satisfaction. There were no significant outcomes. Likewise, there was no significant correlation between age and the main variable scores. Thus, apart from the gender variable to be reported later, the participant sample was deemed to be homogenous.

Participants were sought from different regions within the UK but, because of anonymity of individuals and their care homes, the dispersion is not known. At least some completed questionnaires were, however, received from the northwest, the north, the east-midlands, and the southeast of England, and it is known that some of the homes were run by religious organisations (for example, Methodist Homes for the Aged).

\subsection{Materials}

A number of variables were assessed, and we compiled a questionnaire comprising the following scales.

\subsubsection{Life satisfaction (the dependent variable)}

The Life Satisfaction in the Elderly Scale (LSES) of Salamon and Conte (1984), comprising 40 questions made up of 8 sub-scales of 5 questions each (used by kind permission of Dr Salamon, pers. com. 24/10/03). The subsections, along with a sample question in each case, are: daily activities (satisfaction with: "My schedule of activities is ..."), meaning (regarding life as meaningful: "I regard my life as ...”), goals (satisfaction with life achievements: “As I look back on my life, I am ...”), mood (how positive it generally is: "My mood is usually ..."), self-concept ("My intelligence is ...", health (perceived healthiness: "Physically I am ..."), finances (satisfaction with financial status: "I worry about my finances ..."), and social contacts (satisfaction with the level of these: "I find the company of others to be ..."). There are five response options for each question, with variable wording to maintain relevance, scored one through five in a positive (satisfying) direction. Maximum possible score $=200$, minimum $=40$.

Salamon and Conte drew on previous research to compile the most comprehensive scale possible, giving specific acknowledgement to Neugarten, Havighurst, and Tobin's (1961) Life Satisfaction Index "A" and "B" scales. They reported an alpha reliability for the LSES of .93 for the whole scale, and from .60 to .79 for the sub-scales. Two test-retest reliability studies yielded correlations of .67 and .90 respectively. Concurrent validity correlations between seven of the LSES sub-scale scores and those obtained from other measures, including a comprehensive psychological interview and the outcome of a 
physical assessment, ranged from .44 to .66 ( $p<.001$ in each case). We chose the LSES in preference to alternative measures of mood, happiness, well-being, or similar construct, as it seemed to be reasonably accessible to respondents, as well as having adequate criterion-related and content validity. We would regard a high score on this scale as being indicative of a successful transition to residential care.

2.2.1.1. Spirituality. The scale chosen for the present study was the INSPIRIT measure of Kass et al. (1991) comprising just seven items, although one of these comprises a check-list of 12 types of spiritual experience that is only scored once in terms of how much they convinced the individual of God's existence. Example items are: "How often have you felt as though you were close to a powerful spiritual force that seemed to lift you outside of yourself? How close do you feel to God?" A principal components factor analysis carried out on this scale by Kass et al. retained all items in a single scale (Eigenvalue $=4.42 ; 63 \%$ of variance explained; loadings .69 to .85). Alpha reliability was stated as .90 , and the validity when compared with the Intrinsic scale of the Religious Orientation Inventory (Allport \& Ross, 1967) yielded a correlation of .69, but there was no significant relationship with the Extrinsic scale. The number of response options varies between the questions, but the maximum possible score is 28 (minimum =7). MacDonald et al. (1995) stated that the INSPIRIT had three strengths: it was based on both clinical and research experience of the constructors; it is suitably parsimonious; there is a demonstrated empirical relationship between spiritual experience and both psychological and physical health.

When selecting the INSPIRIT from a number of alternative measures, we considered it important that the instrument should be free from bias toward any particular religious creed or denomination.

\subsubsection{Religion sub-scales}

In order to measure other aspects of religion and spirituality, four short subscales were compiled based on questions used by other researchers. Each question had five response options, scored one through five in a positive direction.

(i) Nature and humanity. This was to assess a belief in a greater force than the individual themselves, but without reference to God. Five items were abstracted from the Spiritual Orientation Inventory (Elkins et al., 1988), for example "I believe the human spirit is powerful and will win in the end", and "Nature often inspires in me a solemn sense of awe and reverence". The five response options ranged from "strongly disagree" to "strongly agree", giving a score range for the subscale of 5 to 25.

(ii) Non-organised religion. Four questions were adapted from those used by Mindel and Vaughan (1978), and Krause (1998) to assess the involvement in religious practices in a solitary rather than communal way, such as watching services on television, or reading religious literature. The five response options were based on frequency of actions, yielding a score range of 4 (least) to 20 (most).

(iii) Organised religion. Three items were again adapted from Mindel and Vaughan, and Krause. The questions asked for frequency of actively participating in communal activities such as church services. There were five response options, and a score range 3 (least) to 15 (most).

(iv) Coping religion. Four questions were once again adapted from Mindel and Vaughan, and Krause, but were re-phrased to assess the extent to which participants drew on their faith to help them cope with their change of residence. For example "When dealing with my move to residential care, I have received much personal strength from God". Score range 4 (least) to 20 (most). 


\subsubsection{Other biographical data}

Participants were asked for birth date, gender, and marital status. There was also a single question "Are you a religious person, at least in your own fashion?". There were five response options ranging from "not at all" to "very much", scored on a five-point scale. Finally, participants were asked to state their religious affiliation, if they had no objection.

\subsection{Procedure}

The Christian Council on Ageing (CCOA) is a UK national charitable organisation with a number of aims, including nurturing the continuing development of personal faith and growth, promoting the welfare of the elderly and, in this regard, co-operating with other agencies concerned with ageing, including those of other faiths. A number of CCOA members volunteered to contact residential care homes in their geographical areas, to see whether or not residents of maximum 1 year tenure would be willing to complete a questionnaire on their thoughts, feelings and beliefs. It was anticipated that participants would need assistance in completing the questions, and might require items to be read aloud to them and, if necessary, explained. An "Instructions to helpers" brief was prepared comprising 10 points, emphasising the sensitive nature of some of the items and the need to strictly maintain the ethical principles of no coercion, right of withdrawal, confidentiality, and avoidance of distress. No deception was involved in the survey. The participants and the care homes both remained anonymous.

A total of 140 questionnaires were sent to volunteer helpers on request, along with the brief and stamped-addressed envelopes for return. By the deadline, 50 useable questionnaires had been returned (including 18 administered by three of the authors), along with 9 unusable ones and 33 blanks. This accounts for $65.7 \%$ of those distributed to helpers, which exceeds the figure of $60 \%$ cited by Palmer (1979) as being the minimum acceptable return rate for sociological surveys. However, feedback from helpers suggested that the response rate from potential participants who met our entry requirements was close to $100 \%$. The time taken for completion of each was approximately $1 \mathrm{~h}$. Some participants volunteered additional comments, and these were noted.

Responses were coded for subsequent statistical analysis. Inevitably there were instances where individual items were not completed, and it was not our wish that participants be coerced into doing so against their wishes. Where this was excessive, subsections or even the complete questionnaire were excluded from the analyses. In less extreme cases, subscale scores were calculated based on the mean scores of completed items. In practice this meant that only one blank would be filled in a subscale. Where a section had to be excluded, the subsequent statistical analyses will reflect a lower participant total.

\section{Results}

\subsection{Descriptive statistics}

Summary statistics for the LSES and INSPIRIT scales, and for the four religion subscales, are shown in Table 1. It will be seen that scores on all measures are reasonably normally distributed, although ratings of the use of religion as a coping strategy exhibit a modest negative skew. Also, scores on this measure and the LSES show degrees of positive and negative kurtosis respectively. 
Table 1

Mean scores and standard deviations of paranormal belief, control of life events, likelihood of life events and trait anxiety

\begin{tabular}{|c|c|c|c|c|c|c|}
\hline Measure & $M$ & S.D. & Median & Range & Kurtosis & Skew \\
\hline Life Satisfaction in the Elderly Scale & 144.56 & 17.42 & 142 & $114-181$ & -1.03 & 0.136 \\
\hline Elkin's Faith in Nature and Humanity Scale & 20.52 & 2.72 & 21 & $14-25$ & -0.20 & -0.51 \\
\hline Non-organisational Religiosity Scale & 14.32 & 4.53 & 15 & $4-20$ & 0.083 & -0.88 \\
\hline Organisational Religiosity Scale & 7.36 & 3.02 & 7 & $3-15$ & -0.54 & 0.35 \\
\hline Using Religion as a Coping Strategy Scale & 16.51 & 4.62 & 19 & $4-20$ & 1.39 & -1.50 \\
\hline Kass et al.’s Inspirit Spirituality Scale & 19.80 & 5.63 & 20 & $7-28$ & -0.71 & -0.42 \\
\hline
\end{tabular}

The mean LSES score of 144.56 is very similar to the 143.26 previously obtained by Lowis and Raubenheimer (1997) in their study of elderly men. It is, however, somewhat higher than the 124.00 for the 50\% quantile reported by Salamon and Conte (1984) from their norm sample of participants aged 80 and over, suggesting that the present sample represented a more satisfied cohort. The mean INSPIRIT score at 19.80 is very close to the 19.60 reported by Kass et al. (1991) from their reliability sample aged 25 to 72 , but slightly lower than the 22.17 obtained by Lowis and Hughes (1997) in their study of retired men and women.

In response to the question on religious affiliation, only $14 \%$ of participants responded "none" (a further $2 \%$ did not respond to this). The mean score for the question on how religious the person considered themselves to be, on a scale of one to five was 3.92. Interestingly, only $8 \%$ responded "not at all", which is less than the percentage who declared that they had no religion. This seems to offer some support for the contention that it is possible to have a faith in a higher power whilst not being aligned to orthodox religion.

\subsection{Hypothesis testing}

Zero order correlations (Pearson) for all the scales and subscales are given in Table 2. Predicted positive and significant relationships were found between scores from the LSES and INSPIRIT scales, and between the former and scores from both the nature/humanity and the coping religion subscales (all two-tail), although the INSPIRIT result would reduce to non-significance if corrected for multiple analysis. Interestingly, neither the organised nor non-organised religion subscales exhibited a significant

Table 2

Pearson correlations between measures (with 2-tailed probabilities)

\begin{tabular}{llllll}
\hline & $\begin{array}{l}\text { Elkin's Faith } \\
\text { in Nature and } \\
\text { Humanity Scale }\end{array}$ & $\begin{array}{l}\text { Non-organisational } \\
\text { Religiosity Scale }\end{array}$ & $\begin{array}{l}\text { Organisational } \\
\text { Religiosity } \\
\text { Scale }\end{array}$ & $\begin{array}{l}\text { Using Religion Kass et al.'s } \\
\text { as a Coping } \\
\text { Strategy Scale }\end{array}$ & $\begin{array}{l}\text { Inspirit Spirituality } \\
\text { Scale }\end{array}$ \\
\hline $\begin{array}{l}\text { Life Satisfaction in the } \\
\text { Elderly Scale }\end{array}$ & $0.461(0.001)$ & $0.148(0.337)$ & $0.215(0.156)$ & $0.409(0.004)$ & $0.316(0.033)$ \\
$\begin{array}{l}\text { Elkin's Faith in Nature and } \\
\text { Humanity Scale }\end{array}$ & & $0.538(0.001)$ & $0.299(0.051)$ & $0.626(0.001)$ & $0.651(0.001)$ \\
$\begin{array}{l}\text { Non-organisational } \\
\text { Religiosity Scale }\end{array}$ & & $0.541(0.001)$ & $0.695(0.001)$ & $0.705(0.001)$ \\
$\begin{array}{l}\text { Organisational Religiosity Scale } \\
\text { Using Religion as a Coping } \\
\text { Strategy Scale }\end{array}$ & & & $0.388(0.008)$ & $0.383(0.010)$ \\
\hline
\end{tabular}


correlation with life-satisfaction, contrary to prediction. Significant inter-correlations occurred between other combinations of scales and subscales, although these were not part of the guiding hypotheses of this study.

Correlations utilising the single question on how religious a person considered him- or herself to be yielded significant relationships with the mood $(r=.366, p=.009)$, and the physical health $(r=.405$, $p=.004)$ subscales of the LSES. These effect sizes would be classed as medium to large (Cohen, 1988). This provides some degree of confirmation for the notion that people who hold religious beliefs enjoy higher perceived levels of both mental and physical health, than do those who do not hold such views. A significant correlation was also obtained between how religious a person considered him- or herself to be and the meaning in life sub-scale $(r=.310, p=.028)$, but there were no significant relationships involving the remaining five subscales. (Note: these exploratory computations were not corrected for multiple analyses).

Although there was no significant gender effect with regard to the main variable, there was a significant gender difference concerning the use of religion as a coping mechanism (mean female $=17.97$, male $=12.69, t=2.93(13.78), p=.011)$.

\subsection{Path analysis}

Taken together the correlations shown in Table 1 suggest that there is no direct relationship between organisational and non-organisational religiosity and life satisfaction, although the reasonably strong correlations they share with other variables suggest that there could be a mediated effect. To explore this suggestion, a path analysis was conducted, and the outcome is shown in Fig. 1. These results were obtained through successive stepwise multiple regression analyses with LSES scores as the initial criterion and each predictor from previous analyses serving as the criterion for the next stage of regressions with the remaining variables. The path coefficients represent standardised partial regression coefficients $(\beta$ weights). Non-significant relationships with LSES scores are given as dashed lines for information.

It is evident from the figure that the only factor to significantly predict participants' scores on the measure of life satisfaction in the elderly (LSES) was their score on Elkin's faith in nature and humanity (Faith). None of the other variables added significantly to the amount of variance in LSES accounted for by Faith scores. However, tendency to use religion as a coping strategy (Coping) was identified as a predictor of Faith when the latter was entered as the criterion, suggesting that the relationship between Coping and LSES might be mediated by Faith. The other factor to originally correlate significantly with LSES scores, INSPIRIT, was found along with participant gender to predict Coping scores. Scores in the non-organisational and organisational religiosity scales, which had not previously been found to predict LSES, are added to the path diagram in later iterations.

\section{Discussion}

This study set out to explore the possible mediatory effects of religion and spirituality on the life satisfaction of elderly people who had recently relinquished independent living arrangements and moved to a residential care home. Not all the outcomes were as predicted, as neither organised nor nonorganised religious involvement was significantly linked with life satisfaction. Interestingly, however, it was the measures relating more to the personal (subjective) dimensions of spirituality, and a faith in 


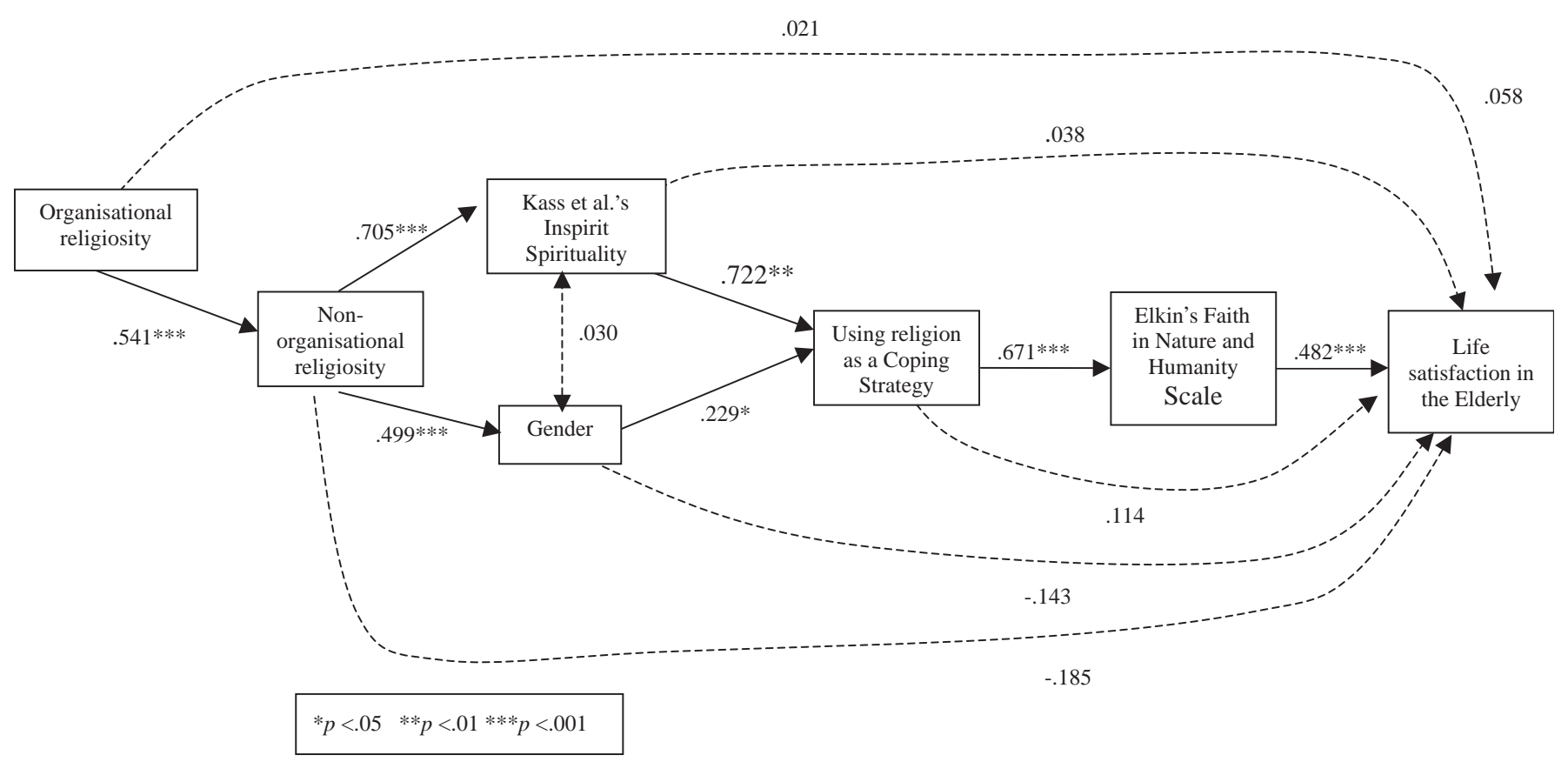

Fig. 1. Path diagram illustrating the interrelationships between life satisfaction in the elderly, gender and measures of religiosity, anxiety and perceived likelihood and controllability of stressful future events. 
nature and the goodness of humanity, that yielded significant (direct) correlations with life satisfaction and coping ability. These findings would agree with those of Kass et al. (1991) and Koenig (2001, 2002) that spirituality is related to life satisfaction, and that religion engenders a feeling of control over health matters and helps elderly in-patients to cope.

Culliford (2002) noted that, although church attendance is low, $76 \%$ of people (age not stated) admitted to spiritual and religious experiences. He cited opinion that there is a spiritual dimension within everyone that goes beyond religious affiliation and strives for inspiration. It is of interest that the present study revealed that only $8 \%$ of participants responded that they were not religious, but $14 \%$ recorded "none" when asked to state religious affiliation. This finding is in sympathy with Koenig's (2002) comment that the non-religious still have spiritual needs, and it also justifies our decision to include broader, non-denominational measures in our study.

Whilst being based only on responses to a single question on the strength of a person's religion, and two subscales of the LSES, there was some support for the notion that one's personal sense of religiosity has a beneficial effect both on mood and perceived (rather than necessarily actual) health, as previously suggested by Kass et al. (1991), Koenig (2002) and Krause (1998). The finding that women scored higher than did men on the use of religion as a coping mechanism is of possible relevance here, and is in keeping with the observation of McCullough, Hoyt, Larson, Koenig, and Thoresen (2000) that spirituality-health links have been shown to be the strongest in females.

Although the trend was in the hypothesised direction, there was no direct support at the significance level normally adopted for the notion that participation in organised religion has a positive effect on life satisfaction, through perceived social support from like-minded associates, as suggested by Cutter (2003), Kahn et al. (2003) and Krause (1998). However, the path analysis attempted to identify any mediating effects of organisational religiosity, and the outcome suggested that it might engender a more subjective experience of spiritual forces and coping resources that can be drawn upon during times of need. An influencing factor could, of course, be restricted opportunity for residents to participate in organised religion whilst in care homes, especially in attending church premises familiar to them. The management of care homes is required to meet the spiritual needs of their residents, although further research is needed to explore how in practice this is carried out. Where available, religious services in the care home would provide some stability and an anchor in times of a major lifestyle change, but may not be as qualitatively satisfying as was previous regular attendance at a familiar church, or if services in the home were conducted by clergy from an unfamiliar denomination.

The correlation between life satisfaction and non-organised religion was likewise in the hypothesised direction, but it was weak and non-significant. This finding would seem initially to disagree with the suggestion arising from a study by Levin and Taylor (1997) that non-organisational religiosity was higher among the over-60s than it was with younger age groups. However, their work concerned the relationship between prayer frequency and mystical experience, rather than with life satisfaction as such. This could be interpreted in terms of an increasing importance of spiritual concerns as one grows older, perhaps at the expense of doctrinal considerations. The present finding of a relationship between life satisfaction and scores on a measure of spirituality would concur with this suggestion.

All the findings and implied conclusions reported above must remain tentative. The number of participants was modest, and generalisation is limited by a lack of randomness in the way participants were recruited from largely unrecorded geographical regions of the UK, based on capacity and willingness to participate. Confidence in the validity and reliability of the measures used was, however, strengthened by our policy of selecting measures that had been used successfully by previous 
researchers, although this may have had its disadvantages. The wording and meaning of some of the questions, especially in the LSES and to a lesser extent the INSPIRIT, could have been difficult for some participants to comprehend. The ages of our respondents ranged from 74 to 94 (mean 85.24), and most of them could therefore be classed as very elderly. Although helpers with the questionnaire administration were instructed not to influence participants in their responses, questions were often read out loud and help was given with the comprehension when requested. For future work, the strategy for data collection will be reviewed in order to avoid such potential bias.

The original reliability studies and normative data compilation for the LSES were conducted with a sample aged 55 to 98 (mean and standard deviation not stated) (Salamon \& Conte, 1984); whilst that for the INSPIRIT was done with a sample aged 25 to $72(M=46.2$, S.D. $=11.2)$ (Kass et al., 1991); it is not known if any assistance was given during administration to the older participants. No help was necessary when the LSES was previously administered by Lowis and Raubenheimer (1997), and the INSPIRIT by Lowis and Hughes (1997). The maximum ages of participants in these cases were $84(M=69.8)$ and 90 $(M=76.7)$ respectively, and all individuals were still living independently. The current participants were somewhat older on average than either of these groups (maximum 94, $M=85.24$ ). Informal feedback from helpers in the present study indicated that the questionnaire as a whole was occasionally seen by some potential participants as being too formidable even to attempt, although most of those who did start ultimately managed to complete all or most of the items. Thus we suspect that we would have had more participants had we produced a shorter or simpler instrument. Of course this would have the disadvantage of restricting the scope and comparability of the measure, which would need to have been tested for reliability and validity, and which would have yielded data not directly comparable with the findings of others.

Because of the significant correlational findings obtained on the role of at least some aspects of religious and spiritual beliefs and practices on life satisfaction and, by implication, successful transition from independent domicile to residential care, further research of greater scope is indicated. This may include a longitudinal study, and would require reconsideration of what measures are appropriate for this age group; a more open-ended, qualitative approach might be justified. As male respondees were relatively under-represented in the present study (although their ratio was in keeping with population trends), greater equity in numbers of male and female participants can be attempted to enable further exploration of possible gender differences.

The need for those who work with older adults to be sympathetic to their clients' religious needs, and be understanding of the importance of religion as an aid to coping, was also emphasised by Krause (1998), who additionally commented on the rapid growth of religious counselling services. Koenig (2001) cited several studies suggesting that religious coping was related to lower rates of depression, and that those with physical disabilities appeared to experience benefits from religion. He added that this may increase motivation toward self-care activities, and that this has implications for patients in nursing homes. Shulmanasy (2002) reported that previous surveys had found that the numbers of patients who felt that physicians should ask them about there spiritual needs ranged from $41 \%$ to $94 \%$, and that this included up to $45 \%$ of those who considered themselves to be non-religious.

The main finding of this study relates to the benefits of a more personal and subjective belief system, than to a formal or even informal involvement with orthodox religion, although the possible mediating effect of the latter is a novel outcome of this research. It is thus important that those who work with older people either as carers, clinicians, care home managers, social policy makers or, simply, as concerned friends and family, acknowledge and recognise the role that religious and spiritual beliefs may have in 
helping the elderly cope with change and other traumatic events, and allow opportunity for this to occur. What might sometimes be seen as disengagement, or periods of introspection, may in fact simply be evidence of coping mechanisms at work.

Brown and Lowis (2003) found some empirical confirmation of a developmental stage beyond that of Erikson's (1988) stage eight - ego integrity versus despair (as mooted by Erikson's wife Joan, and others), that only occurs in the very old. Brown and Lowis concluded that this suggested a potential psychological and (perhaps) spiritual growth throughout the lifespan, regardless of how many years this may last. They argued that such knowledge can help us to understand what may sometimes underlie the superficial behaviour of the elderly; the present findings add the additional possibility that this may be evidence of coping mechanisms at work.

\section{References}

Allport, G. W., \& Ross, J. M. (1967). Personal religious orientation and prejudice. Journal of Personality and Social Psychology, 5(4), 432-443.

Batson, C. D., Schoenrade, P. W., \& Ventis, L. (1993). Religion and the individual. New York: Oxford University Press.

Bee, H. L. (1998). Lifespan development. Harlow: Longmans.

Bentley, L. A. A. (1991). The use of a stress coping mechanism for college student perceived stresses in the college environment. Dissertation Abstracts International, 52(4), 1218-A.

Biggs, S. (1993). Understanding aging, images, attitudes, and professional practice. Buckingham: Open University Press.

Brown, C., \& Lowis, M. J. (2003). Psychosocial development in the elderly: An investigation into Erikson's ninth stage. Journal of Aging Studies, 17, 415-426.

Cohen, J. (1988). Statistical power analysis for the behavioural sciences (2nd edn.). Hillsdale, NJ: Erlbaum.

Culliford, L. (2002). Spirituality and clinical care. British Medical Journal, 325, 1434-1435.

Cutter, J. A. (2003). Spirituality may help people live longer. http:www.theselfimprovementsite.com/spiritual.html (accessed $18 / 12 / 03)$.

Elkins, D. N., Hedstrom, L. J., Hughes, L. L., Leaf, J. A., \& Saunders, C. (1988). Toward a humanistic-phenominological spirituality. Journal of Humanistic Psychology, 28(4), 5-18.

Erikson, E. H. (1988). The life cycle completed. Extended version with new chapters on the ninth stage by Joan M. Erikson. New York: Norton.

Holmes, T. H., \& Rahe, R. H. (1967). The social readjustment rating scale. Journal of Psychosomatic Research, 11, $213-218$.

Holmes, T. S., \& Holmes, T. H. (1970). Short-term intrusions into the life style routine. Journal of Psychosomatic Research, 14, $121-132$.

Kahn, J. H., Hessling, R. M., \& Russell, D. W. (2003). Social support, health, and well-being among the elderly: What is the role of negative affectivity? Personality and Individual Differences, 35, 5-17.

Kass, J. D., Friedman, R., Leserman, J., Zuttermeister, P. C., \& Benson, H. (1991). Health outcomes, and a new index of spiritual experiences. Journal for the Scientific Study of Religion, 30(2), 203-211.

Koenig, H. G. (2001). The healing power of faith. New York: Simon and Schuster.

Koenig, H. G. (2002). A commentary: The role of religion and spirituality at the end of life. The Gerontologist, 42, $20-23$.

Krause, N. (1998). Neighbourhood deterioration, religious coping, and changes in health during late life. The Gerontologist, $38(6), 653-664$.

Levin, J. (2001). God, faith and health. New York: Wiley.

Levin, J. S., \& Taylor, R. J. (1997). Age differences in patterns and correlates of frequency of prayer. The Gerontologist, 32, $75-88$.

Lowis, M. J., \& Hughes, J. (1997). A comparison of the effects of sacred and secular music on elderly people. The Journal of Psychology, 131(1), 45-55.

Lowis, M. J., \& Raubenheimer, J. (1997). Ego integrity and life satisfaction in retired males. Counselling Psychology in Africa, $2,12-23$. 
MacDonald, D. A., Le Clair, L., Holland, C. J., Alter, A., \& Friedman, H. L. (1995). A survey of measures of transpersonal constructs. The Journal of Transpersonal Psychology, 27(23), 171-231.

McCullough, M., Hoyt, W., Larson, D. B., Koenig, H. G., \& Thoresen, C. (2000). Religious involvement and mortality: A meta-analytic review. Health Psychology, 19(3), 211-222.

Mindel, C. H., \& Vaughan, C. E. (1978). A multi-dimensional approach to religiosity and disengagement. Journal of Gerontology, 33(1), 103-108.

Neugarten, B. L., Havighurst, R. J., \& Tobin, S. S. (1961). The measurement of life satisfaction. Journal of Gerontology, 16, $134-143$.

Nicholson, M., \& White, D. (1993). Old people's homes: The relative's view. British Medical Journal, 306(6882), 918-920.

Oldman, C., \& Quilgars, D. (1999). The last resort? Revisiting ideas about older people's living arrangements. Ageing and Society, 19, 363-384.

Palmer, J. (1979). A community mail survey of psychic experiences. Journal of the American Society for Psychical Research, $73,221-251$.

Rahe, R. H., \& Arthur, R. J. (1978). Life changes and illness studies: Past history and future directions. Journal of Human Stress, 4, 3-15.

Salamon, M. J., \& Conte, V. A. (1984). Salamon-Conte Life Satisfaction in the Elderly Scale (LSES). Odessa, FL: Psychological Assessment Resources Inc.

Schaie, K. W., \& Willis, S. L. (1996). Adult development and aging (4th edn.). New York: HarperCollins.

Shulmanasy, D. (2002). A biopsychosocial-spiritual model for the cure of patients at the end of life. The Gerontologist, 42, $24-33$.

Towers, C. (2003). Living through transition: The concerns of older people as they relocate to residential care. Doctoral thesis in progress. Nottingham: Nottingham Trent University.

Wanklyn, P. (1996). Homes and housing for elderly people. British Medical Journal, 313(7051), 218-221.

Wilson, G. (2000). Understanding old age. London: Sage.

Worthington, E. L., Kurusu, T. A., McCullough, M. E., \& Sandage, S. J. (1996). Empirical research on religion and psychotherapeutic outcome: A 10 year review and research prospectus. Psychological Bulletin, 119, 448-487. 